\title{
AN INVESTIGATION ON THE IMPROVEMENT OF CONSTRUCTION EXPENDITURE FORECASTING
}

\author{
Andrew ROSS ${ }^{\mathrm{a}}$, Katie DALTON ${ }^{\mathrm{a}}$, Begum SERTYESILISIK ${ }^{\mathrm{b}}$ \\ ${ }^{a}$ School of Built Environment, Liverpool John Moores University, Cherie Booth Building, Liverpool, UK \\ ${ }^{b}$ Faculty of Architecture, Istanbul Technical University, Istanbul, Turkey
}

Received 10 Aug. 2011; accepted 8 Dec. 2011

\begin{abstract}
This study aims to determine the accuracy of the cash flow models and to investigate if these models could be more accurate if they accounted for the potentially influential variables specific to individual construction projects. An analytical case study research strategy has been implemented in collecting data for the construction projects. The data collected has been tested against recognised models. Statistical analyses have been carried out on the data for the specified variables, culminating in the potential proposal of an improved model with respect to these identified variables. The results revealed that the independent variables (type of construction, procurement route and type of work) affect the cash flow forecast. The findings suggested that a model could be more accurate with the input of more job-specific variables and that Hudson's DHSS model is best suited to a construction project procured traditionally. Adopting the 'trial and error' approach, Hudson's DHSS model has been recognised as an accurate model that could be adapted slightly, through changing the parameter values. The clients and the contractors are the main beneficiaries approached for this study.
\end{abstract}

Keywords: cash flow forecasting; accuracy; cash flow forecasting models.

Reference to this paper should be made as follows: Ross, A.; Dalton, K.; Sertyesilisik, B. 2013. An investigation on the improvement of construction expenditure forecasting, Journal of Civil Engineering and Management 19(5): 759-771. http://dx.doi.org/10.3846/13923730.2013.793607

\section{Introduction}

Cash flow forecasting management is imperative to the construction industry's success. A substantial amount of research has been carried out on cash flow forecasting, and many models have been produced emphasising the importance of this subject area, whilst at the same time suggesting that an agreed solution is yet to be found. Thus, there is room for improvement on the development of cash flow forecasting techniques. For this reason, this paper aims to determine how accurate the current available cash flow models are and to investigate if these models could be more accurate if they accounted for the potentially influential variables specific to individual construction projects.

\section{Cash flow forecasting}

Cash flow is a measure of a company's financial health (Investor words 2004). The forecasting of construction company cash flow is the prediction of the amount of money that will move through the contracting organisation for that construction project through the duration of the planned program of construction works. A cash flow forecast shows if a firm needs to borrow, how much, when and how it will repay the loan (Business Dictionary 2001).
Gaps between cash outflows and inflows throughout the life cycle of construction projects can create extended periods of low cash availability for a construction contractor, jeopardising the financial stability of the business (Kishore et al. 2011). The importance of cash flow forecasting and management is well recognised in the construction industry; yet, it is not a precise or clear-cut technique, essentially due to the uncertainties and risks associated with construction projects.

Since most companies handle multiple projects simultaneously, managing project finance becomes complicated and tough for contractors (Liu, Wang 2010). Insolvency is more likely to occur in the construction industry than most other industries (Kaka, Price 1993). Supporting this statement, the Construction Statistics Annual Report for 2011, as published by the Office for National Statistics (2011), stated that '2954 construction companies became insolvent in 2010, accounting for $18.4 \%$ of all company cases of insolvency in the UK'. Cash is often seen as the most fundamental and influential of resources on a construction project; as the negative consequences of inadequate cash management more than outweigh the inadequate management of other resources. Russell (1992) stated that 'an excess of $60 \%$ of construction contractor failures are due to economic factors'. A 
construction firm's failure can be due to the failure of one of its projects. The failure of one firm in the construction supply chain of a project can pull other members of the supply chain into insolvency. The major causes of failure tend to be financially based due to a lack of financial control and management. Since the construction industry has a vast array of expertise and experience, this lack of financial control seems unusual and suggests that cash flow managing techniques need improving.

By adopting the most accurate and appropriate cash flow management technique, construction industry companies that would otherwise fall victims to financial difficulties could remain in operation and in fact be financially healthy. Jiang et al. (2011) emphasised the benefits to be gained through formulating a project's cash flow analysis. Cash flow forecasting is used in many industries as a form of budgeting and is an essential management tool for any organisation that seeks to make a profit. Forecasting is slightly different to budgeting, in that, budgeting is more of an active approach and plans for the future, whereas forecasting is more passive and focuses on past experience and estimating from the past data. It is therefore imperative that the forecasting model used is as accurate as possible.

Cash flow forecasts are more often than not carried out at the estimate and pre-tendering stages, and so they are not a precise reality. Cash flow forecasts also fall short in that they do not account for time delays for costs and earned values, and they are not always compatible with integrating variation costs and activities and change factors. Although contract forms specify the extent to which clients may delay payments to contractors, the contractor will need to be able to forecast their cash requirements in relation to what will happen in practice, and this can be affected by individual client behavioural influences. No construction project is likely to ever be in complete accordance with the initial planning, and as such, any cash flow forecasted at the pre-contract stage is unlikely to be completely accurate. There are more than likely going to be discrepancies between forecasted interim measurements/payments and actual progress. It is essential to find a cash flow model that can be adapted to the specific requirements of the project and that includes for the uncertainties relating to the construction business and specific jobsite procedures. Cash flow forecasts are needed at the onsite stage of current contracts and the contracts still to be tendered for. Forecasts are needed at the tendering stage to estimate the finance needed for the project. Contractors, however, often do not have the time, resources or funds to plan detailed schedules before contracts are awarded.

Variables influencing the cash flow are not always accounted for in the simple cost model. Contract conditions and items involved in interim valuations (such as tendering strategies, estimating errors, specific dates of interim payments, subcontractors retention, etc.) are incorporated in a more detailed cash flow model produced by Kaka (1996), and have been shown to influence the cash flow prediction. A cash flow model incorporating data from bills of quantities and construction program details is yet to be developed, and as a result, there is the potential for improvement on the accuracy of the cash flow model. During the construction process, there are many influential factors on the cash flow, namely, cost overruns, time delays, variations and technical changes. The aim for cash flow forecasting is to provide as accurate, flexible and comprehensible forecast as possible. For this to happen, the cash flow model needs to be developed to account for these influential variables. Factors that would be expected to influence cash flow would be those factors that affect the timing of expenses occurring for construction works. It would be expected that variables affecting the workload at commencement would influence valuations at commencement (e.g. the construction type). Another consideration would be the variable of procurement route chosen as the procurement route can determine whether greater expense is occurred at the design stage, pre- construction, post-contract stages or towards the completion of construction.

There are several approaches to methods for cash flow forecasting, the examination of sources of expenditure method, the simpler method (consisting of the decomposition of areas of cost into labour, material, plant and overheads), the mathematical model method (of which some have been based on the theoretical analysis of the behaviour of project expenditure flow), and others on the analysis of data obtained from past projects, e.g. Hudson (1978), Kaka and Price (1993). The latter approach is the method adopted for the current research. Many models have been developed for contractors for preparation of pretender cash flow forecasts, most of which are based on standard S-curves representing the running cumulative values of construction contracts. The fact that many cash flow models have been developed reveals not only how important a subject area this is but also suggests that an agreed universal solution is yet to be found. Thus, there is room for improvement on the development of cash flow forecasting techniques. Within the scope of this paper, the following models have been presented: Hudson (1978), Sears (1981), Kenley and Wilson (1986), Skitmore (1992), Kaka (1996), Khosrowshahi (2001), Kaka and Fortune (2002) and Kaka and Lewis (2003).

Hudson (1978). Hudson, in 1978, was one of the first authors to develop a cash flow model for the cash flows forecasting, and he developed the two parameter 'DHSS (the British Department of Health and Social Security) expenditure model' that is the model most widely used for expenditure forecasting. Hudson developed the model after the analysis of data produced from a large sample of hospital projects, providing values of parameters over a range of project sizes. The Building Cost Information Service uses an 'S-curve' formula, based on work done by the Hudson for the DHSS model, to calculate cash flow forecasts. This S-Curve equation is:

$$
Y=S\left(x+C x^{2}-C x-\left(6 x^{3}-9 x^{2}+3 x\right) / K\right),
$$

where $Y$ is the cumulative monthly value of work executed before deduction or retention of money or addition of fluctuations; $x$ is the proportion of the contract completed, expressed as the month in which expenditure $Y$ occurs 
divided by the contract period; $S$ is the contract sum; $C$ and $K$ are the set parameters that determine the shape of the $S$ curve (BCIS, Building Cost Information Services, website 2011).

The changing of the $C$ and $K$ parameter values can be values chosen to optimise the cash flow forecast and to best suit the individual construction project. According to Hudson (1978), different parameter values should be applied to different types of construction. Altering parameter $C$ changes the build-up time and run-down period, and altering parameter $K$ affects the rate of expenditure over the central part of the graph. Hudson focused his model on the 'contract value' variable and, thus, altered the $C$ and $K$ parameters to reflect the contract value. Kenley (2003) summarised the characteristics of the model as follows:

'They expressed value in terms of time... They argued that all projects have properties of "rate of expenditure" in common... They expressed both axes on a scale to a maximum of ratio $1.0(100 \%)$ '.

Sears (1981) model. As stated by Park (2004), Sears (1981) produced a cash flow technique based on manual integration of the schedule and cost items, reflecting the relationship between activities and cost items, although the method has a slight discrepancy in the time lag between the use of a cost item and payment for it.

Kenley and Wilson (1986). Kenley and Wilson's study followed on from de Groot (1969), who claims that '....if one seeks to conduct a scientific investigation into an individual, unique phenomenon...the regular methodology of (natural) science provides no help'. Kenley and Wilson (1986) adapted this to construction projects as construction projects are unique, and hence, their cash flows should be considered as unique too. Kenley and Wilson produced a cash flow model in 1986, that took account of the variables: contract sum $(V)$ and the percentage of time complete $(d)$. Kenley-Wilson equation is (Skitmore 1992):

$$
V=100 F /(1+F),
$$

where: $F=e^{a}[d /(100-d)]^{b} ; a$ and $b$ are constants.

The slight flaw apparent with this model is that when the project is complete, hence the percentage of time complete is $100 \%$, the value of $(100-d)$ will equal zero, causing an error in the calculation. Therefore, it would be necessary to omit the final monthly valuation from the study, where the project is fully complete.

Skitmore (1992). In 1992 Skitmore researched the application of the DHSS cash flow model to a selection of completed construction projects categorised into four distinct construction methods: steel-framed low rise buildings, new build housing developments, housing refurbishment projects and multi-house 'pre-paint' maintenance contracts. Skitmore was following on from work carried out by Peer (1982), where an analysis of a small data set suggested that similar building type projects produced similar expenditure patterns regardless of the project size. Skitmore (1992) was concerned with how projects were categorised into different building type groups especially in relation to the DHSS formula. Skitmore (1992) carried out an analysis on 27 completed projects, where he used a method of successive approximation to obtain the best parameter values for each project, then he applied these to a standard linear multiple regression to analyse and predict model parameters via the value of works, duration of works, and project type group. He concluded with using a nonlinear technique to find the best set of predictors for each model for projects outside of the data base. Skitmore (1992) found that by applying the best relevant determined parameter values to the cash flow models, the predictive power of the models improves and he stated that 'the cash flow prediction could be ten times an improvement compared to the published forecasted values based merely on the project size'.

Kaka (1996). In 1996, Kaka initially investigated the sensitivity of the cash flow profile to the independent variable of payment delays, using a sample size of 15 construction companies. Kaka (1996) concluded that time delays were more often than not controllable through contract conditions, resulting in the variability being rather limited. From this research, it was felt that too simple models as these were not reliable enough and that it would be good progress to develop a model with sufficient flexibility to incorporate a wide range of variable profiles. Following on from this initial study, Kaka (1996) went on in the same year to develop a 'second generation' cash flow model, incorporating up to fifty variables (over five times the number of variables accounted for in the traditional models) and Kaka was able to conclude that many of the additional variables were influential and should be accounted for in further models.

Khosrowshahi (2001). Khosrowshahi (2001) looked at the structure of the project cash flow forecasting model and provided details of the model that comprised of the mathematical expression and database of past project expenditure flows. The methodology he used for the model development was that of analysing the shape of the s-curve profile. This was carried out in two distinct steps: identifying variables associated with the shape of the expenditure profile, the shape variables and developing a mathematical expression that combined with the shape variables generating the pattern. Khosrowshahi (2001) developed a mathematical model intended to comply with both the recognised characteristics of a growth profile and the specific characteristics of shape profiles. Khosrowshahi (2001) focused on the basis that 'the unpredictability associated with a construction project gives rise to the need for a proactive approach to risk management and risk appraisal'. The mathematical model he used was:

$$
Y c=e b x a(1-x) d-1,
$$

where $Y c$ is the periodic value and $X$ is the proportion of period over the number of periods.

Kaka and Fortune (2002). Kaka and Fortune (2002) acknowledged a flaw in previous studies, essentially that both generations of models relied on a step-by-step simulation of the cash flow mechanism and in an attempt to correct this, they developed a net cash flow model that incorporated many more of the variables featured in the 
cash flow mechanism. Traditional cash flow forecasting techniques had incorporated simulation of s-curves, predicting the cash flow in and out of the organisation through the construction period. Kaka and Fortune (2002) stated that 'it is well recognised that this s-curve approach does not account for influential factors such as construction programme, contract value, construction type and other contract documentation details'. Kaka and Fortune (2002) used a multi-linear regression technique as an alternative to traditional cash flow forecasting models. Their study concluded that 'multi-linear regression does not seem to be an applicable tool to develop contractor's cash flow mechanisms'.

Kaka and Lewis (2003). Following on from Kaka's technique from 1994 of addressing some of the difficulties prevailing from computer simulations for predicting the form of future contracts, Kaka and Lewis (2003) suggested that at company level previously, budgeting is performed on an overall company basis and individual contracts are not considered standing alone, and the models available at project level considered too simple and not able to include essential cash flow variables. In response to these findings, Kaka and Lewis (2003) proposed a dynamic cash flow forecasting model to assist contractors in planning and managing projects at a company level. The proposed model consisted of three key developments, namely, a more accurate and complex cash flow calculation mechanism, information system to assist the contractor with the input of data, and a model based on projects, both known and unknown to the contractor at the time of forecast. As opposed to forecasting contractor's turnover and converting them into monthly cash flows, they used a technique that generated and integrated individual projects with randomly produced start dates.

Literature review revealed that many authors have looked at approaches to cash flow forecasting several times, each successive time with an aim to develop further their previous model or improve their findings. Many of the previous studies looked into cash flow modelling, and they have only used small samples of data to draw conclusions from, whether this is because construction projects are unique and only a small sample are able to be equally compared, or whether this is because most models developed are only able to produce accurate and ideal curves when applied to a small selected few samples. It is apparent that only a small number of previous studies have used adequately sized samples of data sets to draw conclusive opinions and findings from.

\section{Research methods}

The aim of the paper is to initially determine how accurate the current available cash flow models are and to further investigate if these models could be more accurate if they accounted for the potentially influential variables specific to individual construction projects. The objectives of this study are to assess the influence of independent variables on the cash flow models and to develop a model that incorporates the identified variables, making it specific for individual construction projects, in the hope of improving the accuracy of the cash flow model.

Null Hypothesis is: 'The independent variables have no effect on the cash flow model'. This hypothesis has been broken down into three subsidiary hypotheses to further investigate the detailed effect of specific variables on the cash flow forecast model. These subsidiary null hypotheses are:

- Analysis set 1 Null Hypothesis: There will be no association between the 'type of work' and the cash flow forecast.

- Analysis set 2 Null Hypothesis: There will be no association between the 'type of construction' and the cash flow forecast.

- Analysis set 3 Null Hypothesis: There will be no association between the 'procurement route' and the cash flow forecast.

An analytical case study research strategy has been implemented in collecting the data for the construction projects. The cash flow data from completed construction projects was obtained from two professional quantity surveyor firms in the UK. The data was obtained for regional projects and categorised by location. The data sample set obtained initially consisted of 108 completed construction projects, although 6 of these projects had unusual issues (e.g. a contractor became insolvent part way through the works). These six projects were not included in the final data set as it was expected that they may produce anomalous results. The final data sample set contained 102 projects. The independent variables have been identified to categorise each construction project (Table 1). These eight independent variables comprised the causes, and the dependent variable 'cumulative

Table 1. Independent variables and their categorisation

\begin{tabular}{l|l}
\hline Independent variables & $\begin{array}{l}\text { Categorisation of independent } \\
\text { variables }\end{array}$ \\
\hline Works & $\begin{array}{l}\text { New build, refurbishment ora } \\
\text { mixture of both }\end{array}$ \\
\hline Location & $\begin{array}{l}\text { The North West, Oxfordshire, } \\
\text { Bristol, London and } \\
\text { Birmingham }\end{array}$ \\
\hline Commencement date & Yearly quarters \\
\hline Length of contract & Months \\
\hline Type of construction & $\begin{array}{l}\text { Steel frame, timber frame, } \\
\text { traditional construction and in } \\
\text { situ concrete frame }\end{array}$ \\
\hline Facility use & $\begin{array}{l}\text { Schools, colleges, housing, } \\
\text { hospices, retail space, offices, } \\
\text { apartments, hotels and } \\
\text { commercial space }\end{array}$ \\
\hline Type of client & Either public or private client \\
\hline Procurement route & $\begin{array}{l}\text { Traditional contracts, design } \\
\text { and build contracts, project } \\
\text { partnering contracts or a small } \\
\text { few private developments }\end{array}$ \\
\hline &
\end{tabular}


construction cost' was the effect identified for each project. The eight independent variables were categorised into distinct forms of the variable (Table 1). The data has been tested against the DHSS and Kenley and Wilson (1986) model, and statistical analyses have been carried out on the data for the specified variable, culminating in the potential proposal under the 'Data Analysis and Discussion' heading of an improved model with respect to these identified variables.

The cumulative construction valuation was recorded

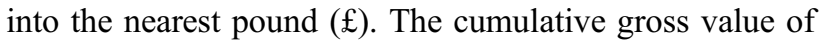
work carried out, before adjustments for retention, was used, since these adjustments for percentage of retention applied to contracts can vary in contracts and may have distorted the model in trying to find a general trend.

From the eight independent variables identified in Table 1, a couple (location and start date) have been rebased to standardise the data sets. The data was rebased in relation to the location and start date independent variables, to ensure no bias in the results for the projects and the most accurate results and findings. The start date would be influential as it is affected by inflation and the current economic climate at the time, and the location for the project will influence construction costs significantly. In order to rebase the data for location, data obtained from the BCIS (2011) has been collected to find the factor to multiply results by Table 2 .

In order to rebase the data for start date, the data was categorised into yearly quarters, ranging from the 2nd quarter 2002 to the 2nd quarter 2009, and then the collection of data was multiplied by the relevant factor to bring all the data to today's date to ensure no bias in the analysis. (The index for 2nd Quarter 2010 is forecasted at 212).

Following the literature review, the expected most influential variables have been identified as type of construction, procurement route and type of work (new build or refurbishment). Hence, further classifications and investigations have been carried out on these three variables.

Applying Hudson's (1978) DHSS model. Hudson's DHSS model has been applied to the 102 construction projects data, through input of the contract value and the respective values for parameters $C$ and $K$, as determined by the contract sum $(S) Y=S\left(x+C x^{2}-C x-\left(6 x^{3}-9 x^{2}+\right.\right.$ $3 x) / K$ ). The S-curves have been plotted for the Hudson model compared to the actual valuation values for each project, to see at first glance how appropriate the Hudson model is. Initially, a systematic and trial and error process has been applied to the graphs to identify the trends and relationships between models and actual data recorded. Three steps followed in the analysis were to:

- identify any difference in the sets of graphs for the variant of the variable being tested, e.g. for type of construction, is there any visible difference between the shape of the curves for new build and refurbishment;

- acknowledge if either of the tested models tend to match the actual data model better than the other;

- identify what the relationship is shape wise, if any, between the most appropriate model and the actual data curve.

The DHSS has been calculated and plotted using the 'IF' formula and 'SERIES' function:

$$
\begin{aligned}
= & \operatorname{IF}\left(\$ C \$ 6<\mathrm{C} 10, \operatorname{MAXA}(\mathrm{B} 12,0), \$ C \$ 5^{*}(\mathrm{C} 10 / \$ C \$ 6+\right. \\
& \$ \mathrm{C} \$ 7^{*}(\mathrm{C} 10 / \$ C \$ 6)^{\wedge} 2-\$ C \$ 7^{*} \mathrm{C} 10 / \$ \mathrm{C} \$ 6- \\
& 1 / \$ \mathrm{C} \$ 8^{*}\left(6^{*}(\mathrm{C} 10 / \$ \mathrm{C} \$ 6)^{\wedge} 3-9^{*}(\mathrm{C} 10 / \$ \mathrm{C} \$ 6)^{\wedge} 2+\right. \\
& \left.\left.\left.3^{*} \mathrm{C} 10 / \$ \mathrm{C} \$ 6\right)\right)\right) .
\end{aligned}
$$

Table 3 presents application of Hudson's DHSS model.

Applying the Kenley and Wilson (1986) model. The Kenley and Wilson curve has been calculated and plotted using the 'IF' formula and 'SERIES' function:

$$
\begin{aligned}
= & \operatorname{IF}\left(\$ B \$ 5<\mathrm{B} 9, \operatorname{MAXA}(\mathrm{A} 11,0),\left(1 0 0 ^ { * } \left(\left(\operatorname{EXP}(1)^{*}\right.\right.\right.\right. \\
& \left.\left((B 9 / \$ B \$ 5) /(100-(B 9 / \$ B \$ 5))^{\wedge} 1\right)\right) /\left(1+\left(E X P(1)^{*}\right.\right. \\
& \left.\left.\left.\left.\left((B 9 / \$ B \$ 5) /(100-(B 9 / \$ B \$ 5))^{\wedge} 1\right)\right)\right)\right)\right) .
\end{aligned}
$$

For comparing these two models with the actual cash flow model result for each project, it would be possible to find an association between which model might have the more appropriate characteristics to suit the relevant variables identified for each project. The constants $(C, K, a, b)$ as identified in the two models can be altered, and a statistical method of least squares was used to estimate these constants' values. In order to compare the accuracy of fit of the models with the data from the actual projects, and to compare the two models, the statistical comparison of the standard deviation has been calculated. The 'SDY' which is the standard deviation about the estimate of $Y$, as used by Kenley and Wilson (1986), has been used for this study:

$$
\mathrm{SDY}=\sqrt{\left\{\Sigma(Y-Y E)^{2} / N\right\}}
$$

where for this study: $Y$ - actual value at any month; $Y E-$ estimated value; and $N$ - number of months.

Table 2. Location indices from BCIS (2011) to rebase the data for the location factor (Base index is UK mean $=100$ )

\begin{tabular}{l|c|c|c}
\hline Location & Index & $90 \%$ confidence interval & Factor to multiply results by \\
\hline North West & 91 & $91-92$ & 0.91 \\
\hline Oxfordshire & 102 & $101-104$ & 1.02 \\
\hline Bristol & 101 & $101-102$ & 1.01 \\
\hline Birmingham & 93 & $93-94$ & 0.93 \\
\hline Shropshire & 93 & $93-94$ & 0.93 \\
\hline
\end{tabular}


Table 3. Application of Hudson's DHSS model

\begin{tabular}{|c|c|c|c|c|c|c|}
\hline $\mathrm{A}$ & $\mathrm{B}$ & $\mathrm{C}$ & $\mathrm{D}$ & $\mathrm{E}$ & $\mathrm{F}$ & G \\
\hline 1 & & & DHSS & \multicolumn{3}{|c|}{$Y=S\left(x+C x^{2}-C x-\left(6 x^{3}-9 x^{2}+3 x\right) / K\right)$} \\
\hline \multicolumn{7}{|l|}{2} \\
\hline 3 & Contract value & 2 & \multicolumn{4}{|c|}{$\begin{array}{l}0=26,000-130,000 ; 1=130,000-260,000 ; 2=0.26-0.52 \mathrm{~m} \\
3=0.52-1.3 \mathrm{~m} ; 4=1.3-5.2 \mathrm{~m} ; 5=5.2-9 \mathrm{~m}, 6=9-14 \mathrm{~m} \\
7=14-19 \mathrm{~m} ; 8=19-23 \mathrm{~m} ; 9=\text { over } 23 \mathrm{~m}\end{array}$} \\
\hline 4 & Contract sum & 292,545 & \multicolumn{2}{|l|}{ Thousands } & & \\
\hline 5 & Contract period & 5 & Months & & & \\
\hline 6 & $C$ & -0.3 & & & & \\
\hline 7 & $K$ & 4.4 & & & & \\
\hline \multicolumn{7}{|l|}{8} \\
\hline 9 & Months & 1 & 2 & 3 & 4 & 5 \\
\hline 10 & Actual & 47,581 & 94,142 & 185,526 & 238,592 & 292,545 \\
\hline \multirow[t]{13}{*}{11} & DHSS & 53,403 & 128,507 & 206,164 & 267,227 & 292,545 \\
\hline & & \multicolumn{2}{|c|}{ Parameter } & Parameter & & \\
\hline & & $C$ & & $K$ & From & To \\
\hline & 0 & -0.44 & 0 & 5.5 & 26,000 & 130,000 \\
\hline & 1 & -0.37 & 1 & 4.9 & 130,000 & 260,000 \\
\hline & 2 & -0.3 & 2 & 4.4 & 260,000 & 520,000 \\
\hline & 3 & -0.22 & 3 & 3.9 & 520,000 & $£ 1.3$ million \\
\hline & 4 & -0.15 & 4 & 3.6 & $£ 1.3$ million & $£ 5.2$ million \\
\hline & 5 & 0.01 & 5 & 4 & $£ 5.2$ million & $£ 9$ million \\
\hline & 6 & 0.11 & 6 & 3.9 & $£ 9$ million & $£ 14$ million \\
\hline & 7 & 0.16 & 7 & 3.8 & $£ 14$ million & $£ 19$ million \\
\hline & 8 & 0.06 & 8 & 3.3 & $£ 19$ million & $£ 23$ million \\
\hline & 9 & -0.03 & 9 & 3.1 & over $£ 23$ millio & \\
\hline
\end{tabular}

By calculating the SDY for each model, it has been possible to compare the models by identifying the lowest SDY and hence the best fit.

\section{Results and discussion}

The 102 projects have been split into sample sets for comparison of the variables identified and tested. A random sample of profiles has been selected from each of the sample sets to demonstrate the findings. As the vast amount of graphs produced would be too overwhelming within the paper, a concise selection demonstrating findings for each variable has been carried out. The results on the three independent variables are presented under the following sub-headings.

\section{1. 'Works' variable}

The data collected provided the following sample sizes: 60 'new build'; 36 'refurbishment'; and 6 'combination of new build and refurbishment'. From the resulting numbers available for each sample size, it has been seen that the sample size for the 'combination of new build and refurbishment' is too small. Furthermore, the proportion of new build and refurbishment works cannot be identified and split percentage wise. It would prove difficult to compare the projects of this form, as the influence of new build or refurbishment works cannot be quantified within each project. Since the analysis would not be as accurate as needed, it was decided with discretion to eliminate the 'combination of new build and refurbishment' variable.

\subsubsection{Refurbishment construction projects}

A selection of four of the graphs for the refurbishment projects, demonstrating the relationship between the projects and the two respective models, have been chosen to be included in the paper. The graphs for projects 24,64 , 72 and 96 have been presented in the paper (Fig. 1) envisaging that the longer the project, the more potential there is to identify the relationship between the curves.

\subsubsection{New build construction projects}

A selection of four of the graphs for the new build projects, demonstrating the relationship between the projects and the two respective models, have been chosen for the projects $29,46,47$ and 50 for $17,16,18$ and 15 months, respectively, envisaging that the longer the 



Fig. 1. Cash flow curves for projects 24, 64, 72 and 96

project, the more potential there is to identify the relationship between the curves (Fig. 2).

In the initial analysis process for the first analysis set, of visual inspection, it can be seen that consistently, there is a difference in the sets of graphs for 'new build' and 'refurbishment' projects. For the 'refurbishment' projects, from the initial observations, the graphs appear to demonstrate that of the two models applied, the DHSS model tends to provide the most effective model, showing a similar shape to the actual data models. The actual data curves follow the DHSS curve fairly closely, with the DHSS curve tending to be slightly greater than the actual curve consistently. For the 'new build' projects, the initial observations demonstrate that again the DHSS model provides a similar shape to the actual data model, but this time with the two curves crossing over at some point near the project start. It can be seen that the DHSS curve is initially slightly less than the actual curve, and following a point of intersection, the DHSS curve continues on a path slightly greater than the actual data curve.

The initial visual inspection for analysis set 1, regarding 'work' variable, supports the subsidiary hypothesis that type of work (new build or refurbishment) influences the cash flow model. Through collaborating these observations with literature survey, the difference in cash flow models in these two variables (new build or refurbishment) was to be expected and can be supported by the fact that often, refurbishment projects involve a greater amount of expense occurring work from the outset.

\section{2. 'Type of construction' variable}

The data collected provided the following sample sizes: 20 'steel frame'; 34 'traditional'; and 6 'in situ concrete'. From the resulting numbers available for each sample size, it has been seen that the sample size for in situ concrete construction is too small and that findings for this form are less conclusive and that it would be inaccurate to draw conclusions from findings with such a small number of projects.

\subsubsection{Steel frame construction projects}

All graphs (in total 20 graphs) have been plotted. A selection of four of the graphs for the 'steel frame' construction projects, demonstrating the relationship between the projects and the two respective models, have been chosen for the projects 12, 18, 46 and 47 for 21, 21, 16 and 18 months, respectively (Fig. 3).

\subsubsection{Traditional construction projects}

The full 34 graphs have been plotted to compare the actual curve with the DHSS curve, for this variable. A selection of four of the graphs for the traditional form of construction projects, demonstrating the relationship between the projects and the two respective models, have been chosen 

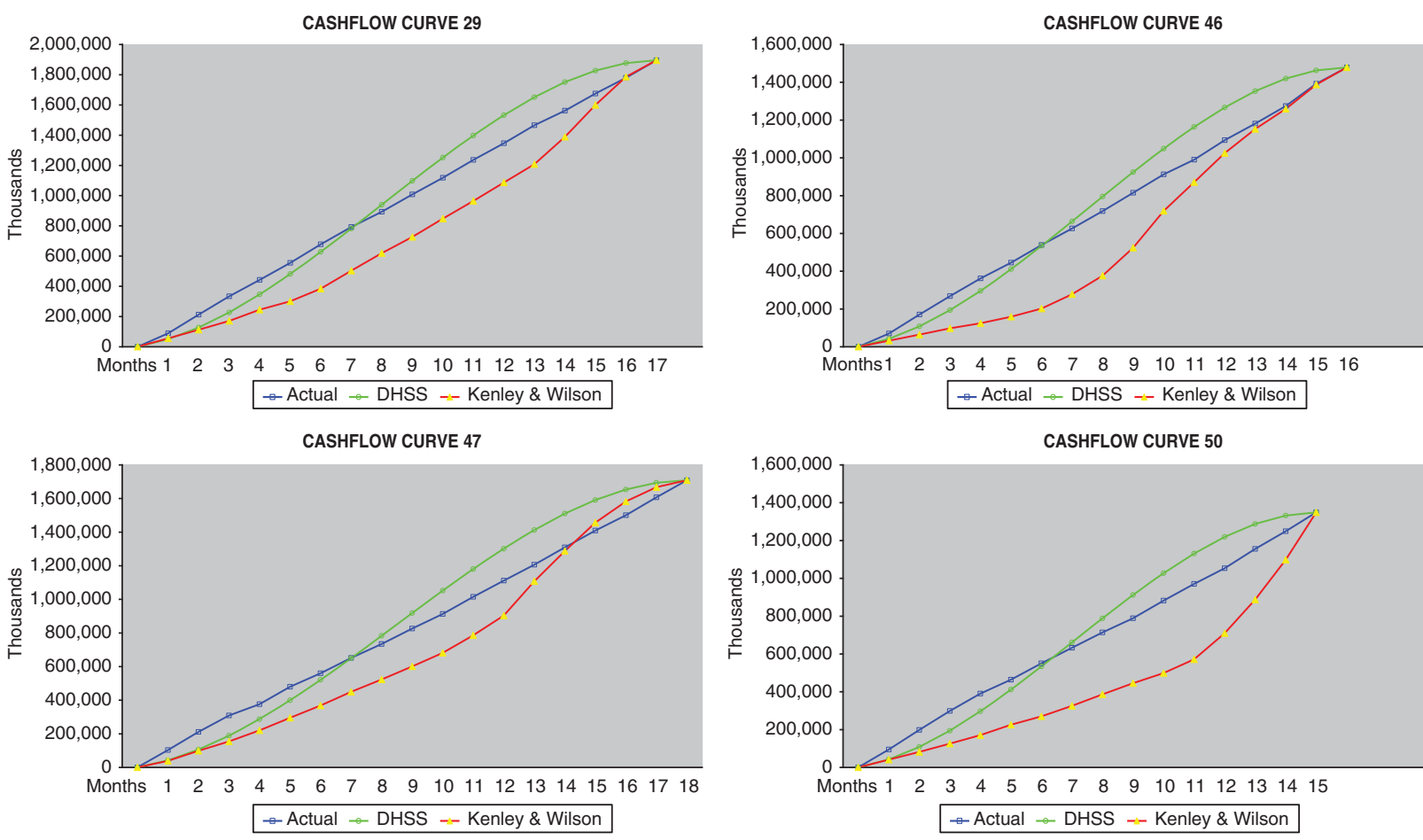

Fig. 2. Cash flow curves for projects $29,46,47$ and 50
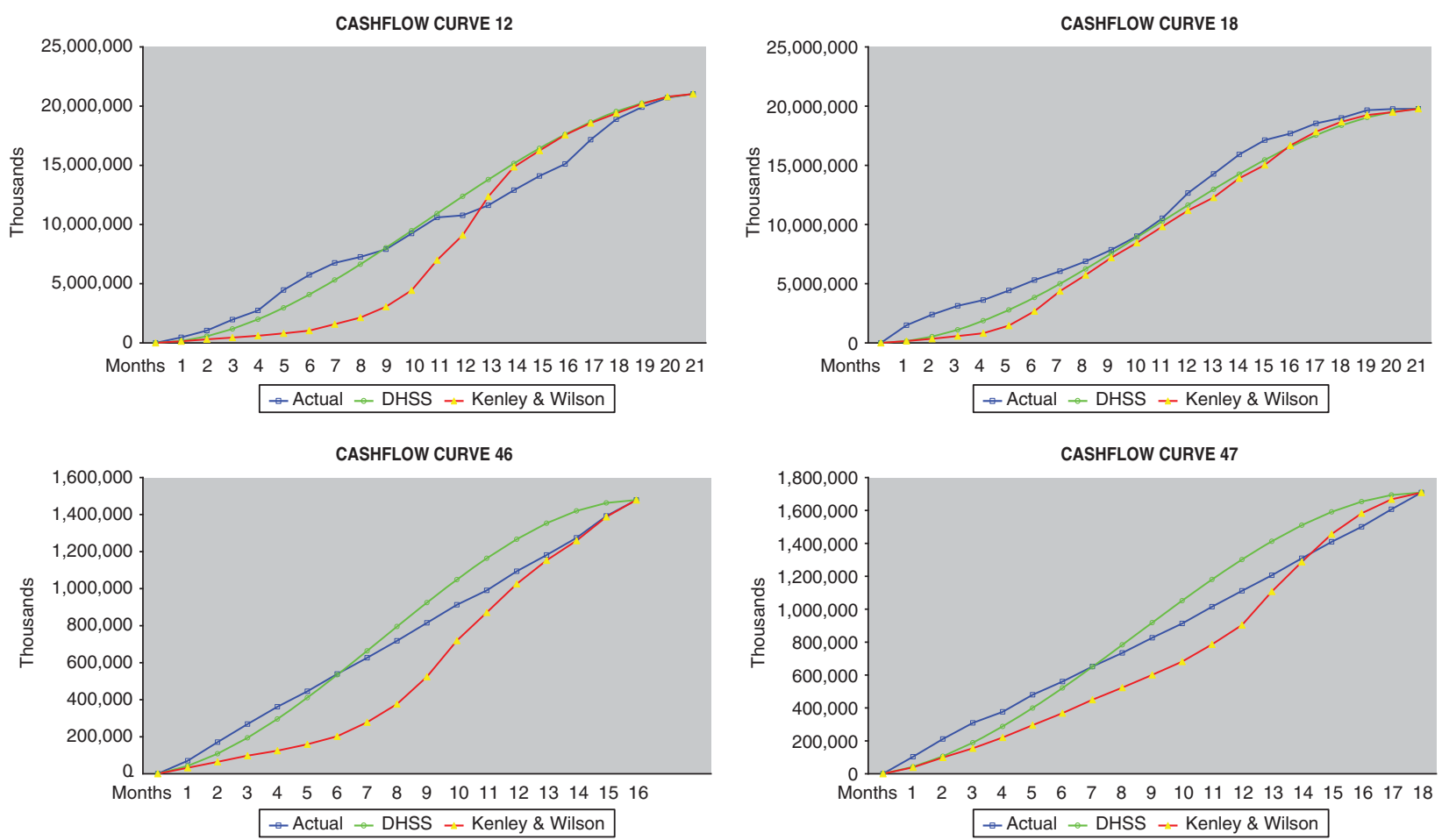

Fig. 3. Cash flow curves for projects 12, 18, 46 and 47

for the projects $75,76,79$ and 80 for $18,11,12$ and 8 months, respectively (Fig. 4).

\subsubsection{In situ concrete construction projects}

The full six graphs have been plotted to compare the actual curve with the DHSS curve. A selection of two graphs for the in situ concrete form of construction projects, demonstrating the relationship between the projects and the two respective models, have been chosen for the projects 19 and 33 for 11, and 6 months respectively (Fig. 5).

In the initial visual inspection analysis of the construction type set of data, there are suggestions that 

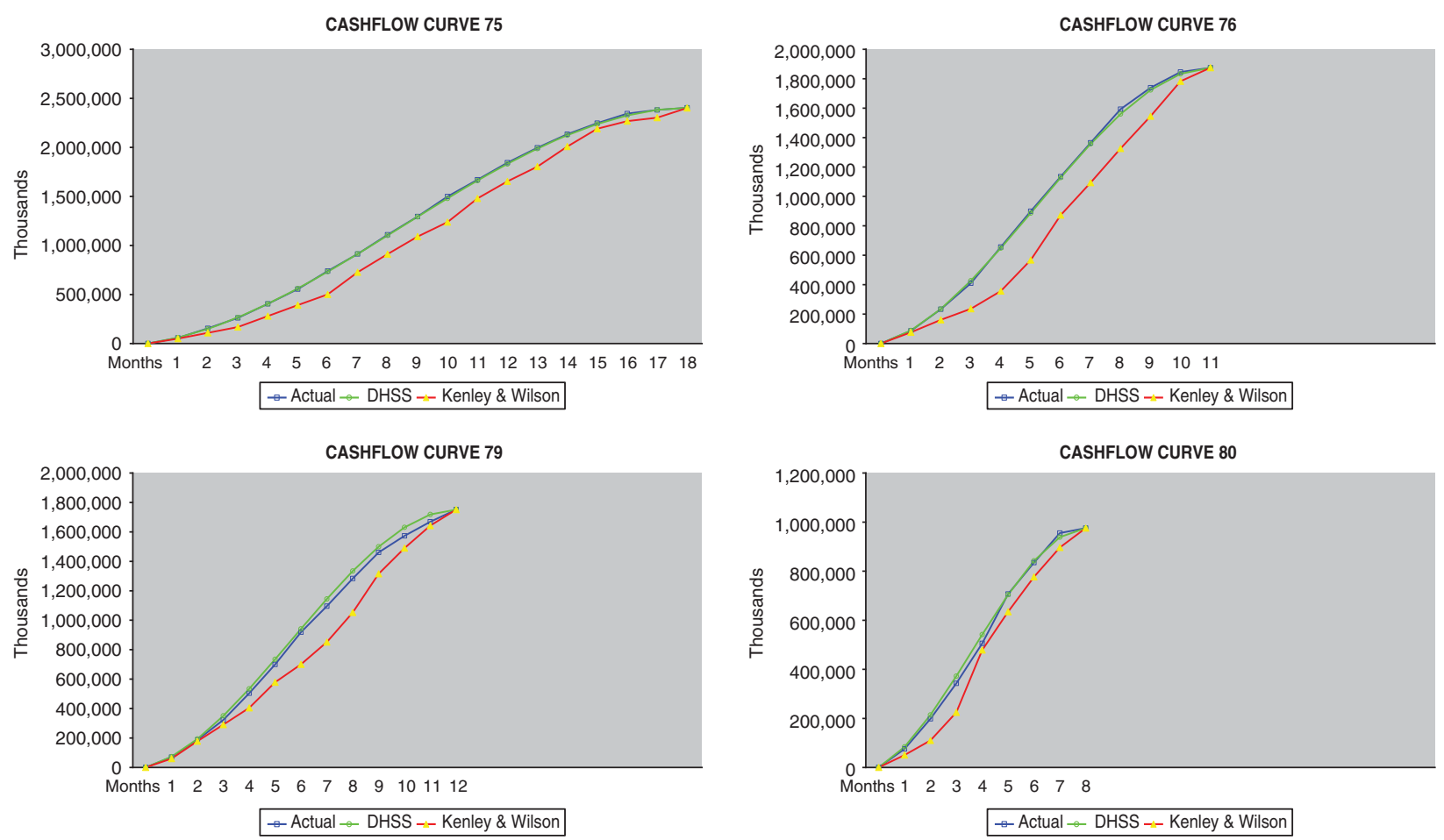

Fig. 4. Cash flow curves for projects $75,76,79$ and 80
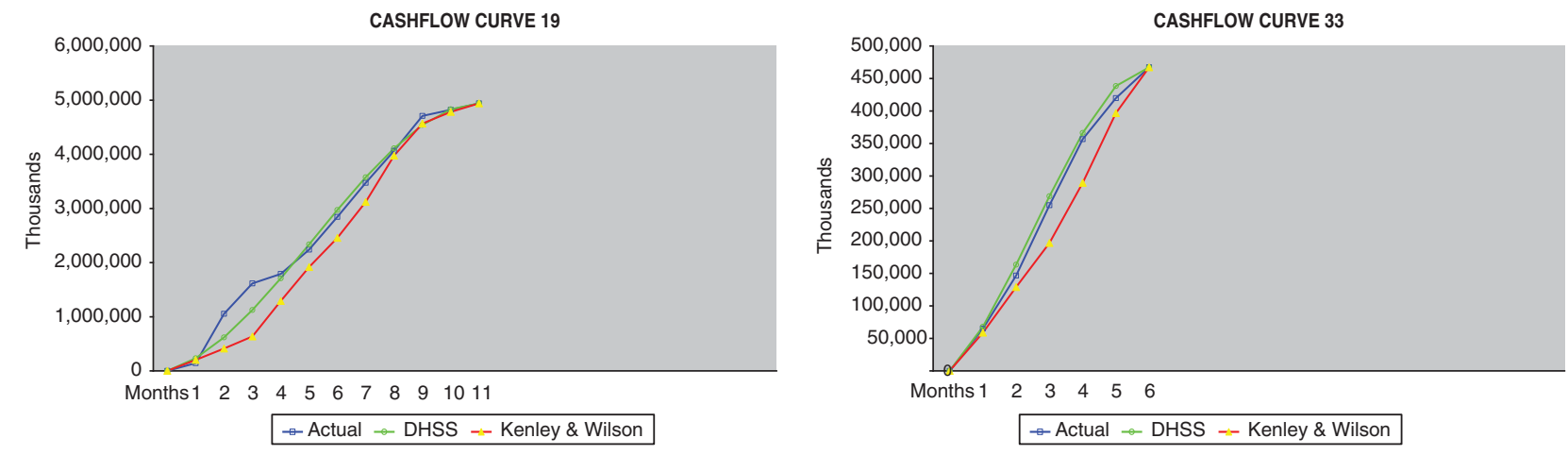

Fig. 5. Cash flow curves for projects 19 and 33

there is a difference in cash flow models depending on the construction method. By comparing the 'steel frame' and 'traditional' types, it can be seen that the traditional method graphs tend to follow the usual ' $\mathrm{S}$ ' curve, and the steel frame models in fact often appear to follow less of an s-curve and more of a constant straight line. There seems to be less of a gradual increase in the value with the steel frame compared to the traditional construction, suggesting that valuations are larger from the outset for the steel frame construction types. For this analysis set, it is again recognised that out of the two simulated models proposed, the DHSS model more often than not provides a similar curve to the actual models. The traditional construction projects appear to follow the DHSS curve closely, even for an 18-month construction project. It suggests that the Hudson model is an accurate estimate for traditional construction projects which on reflection would make sense as the Hudson model was developed in 1978, essentially with traditional construction methods in mind,

as steel frame, timber and concrete construction would have all been relatively new ideas, and not as well considered or utilised as they are today. An analysis of in situ concrete construction would be difficult as the quantity of data produced is not substantial enough to support any analyses.

The initial visual inspection for analysis set 2, regarding 'type of construction', supports the subsidiary hypothesis that the form of construction influences the cash flow model. There is a distinct difference in the cash flow curve recognised between the two main types of construction investigated, namely, traditional and steel frame construction. It is acknowledged that the steel frame models in fact often appear to follow less of an s-curve and more of a constant straight line, and the interim valuations build up more consistently than gradually compared to the traditional construction. The valuations are recognised as being larger from the outset for the steel frame construction types. The findings are in accordance 
with literature survey. The justification for this finding would be supported by the fact that steel is an expensive material, and material costs for constructing a steel frame would result in an initial influx of expense occurring on a construction project.

\section{3. 'Procurement route' variable}

The data collected provided the following sample sizes: 54 'traditional'; 40 'design and build'; 4 'PPC project partnering'; and 4 'private contract'. From the resulting numbers available for each sample size, it was decided with discretion to eliminate the 'PPC' and 'private contracts' from the analysis of procurement type, as the sample size for these two types was insufficient, and it would be inaccurate to make assumptions from them. As a result, the third assessment compared the two most widely used procurement types: 'traditional' and 'design and build'.

\subsubsection{Traditional procurement route projects}

The full 54 graphs have been plotted for this variable to compare the actual curve with the DHSS curve. A selection of four of the graphs for the traditional procurement route projects, demonstrating the relationship between the projects and the two respective models, have been chosen for the projects $15,28,84$ and 96 for 9, 8, 8 and 10 months, respectively (Fig. 6).

\subsubsection{Design and build procurement route projects}

The full 40 graphs have been plotted for this variable to compare the actual curve with the DHSS curve. A selection of four of the graphs for the design and build
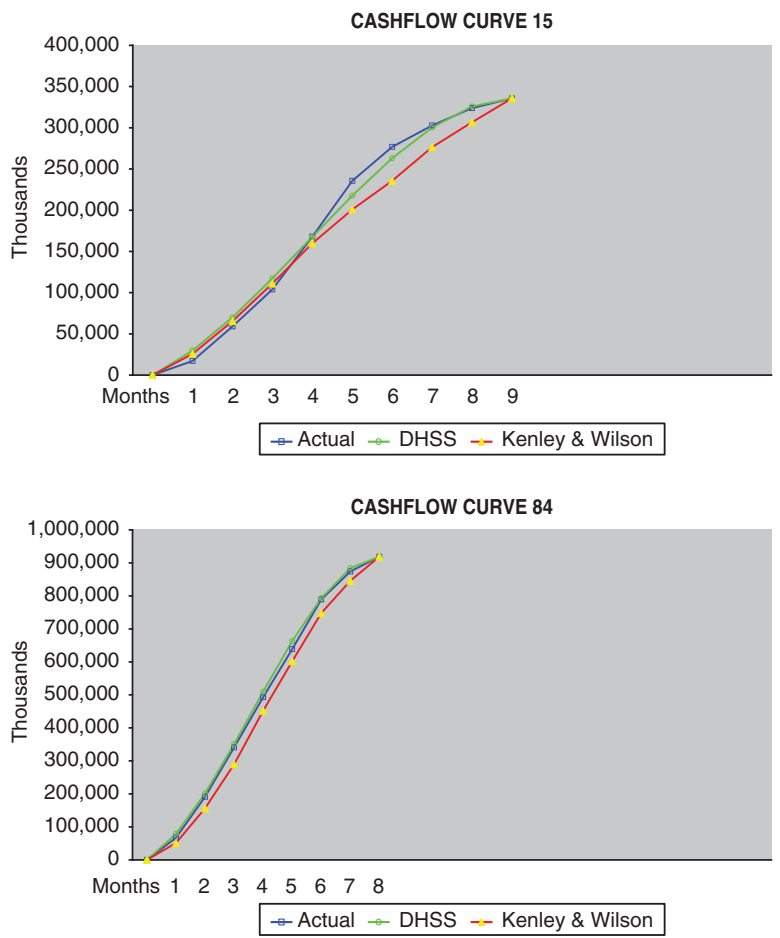

Fig. 6. Cash flow curves for projects 15, 28, 84 and 96 procurement route projects, demonstrating the relationship between the projects and the two respective models, have been chosen for the projects $12,46,66$ and 72 for 21,16 , 14 and 13 months, respectively (Fig. 7).

From the initial visual inspection of the analysis set of procurement route types, the design and build route and traditional route have been compared, showing for both sets that the actual model tends to follow the DHSS model, if it follows either. For the 'traditional' route, it can in fact be seen that the actual model is a very close match for the DHSS model, and the actual models tend to follow the traditional ' $S$ ' curve shape fairly accurately. For the 'design and build' route, it is not apparent or initially obvious from any visual analysis that there is a relationship between the procurement route and cash flow model.

The initial visual inspection for analysis set 3, regarding 'procurement route', supports the subsidiary hypothesis that the type of procurement influences the cash flow model. There tends to be a difference in the curves produced for the two types of procurement researched. The evidence to support this difference is not as substantial or supportive as with the previous two analysis sets. This seems surprising as this analysis set has the largest sample of data collected, and of all the variables being tested, it would have been expected that findings for this variable would have been the most conclusive. Whether this can be explained by anomalous construction projects is something to be further studied. Collaborating these slight findings with research from the literature survey, it would have been expected that the traditional procurement would have followed the traditional ' $S$ ' curve most closely, and design and build would have followed a curve with less on a gradual increase, and potentially more substantial valuations for the offset. The
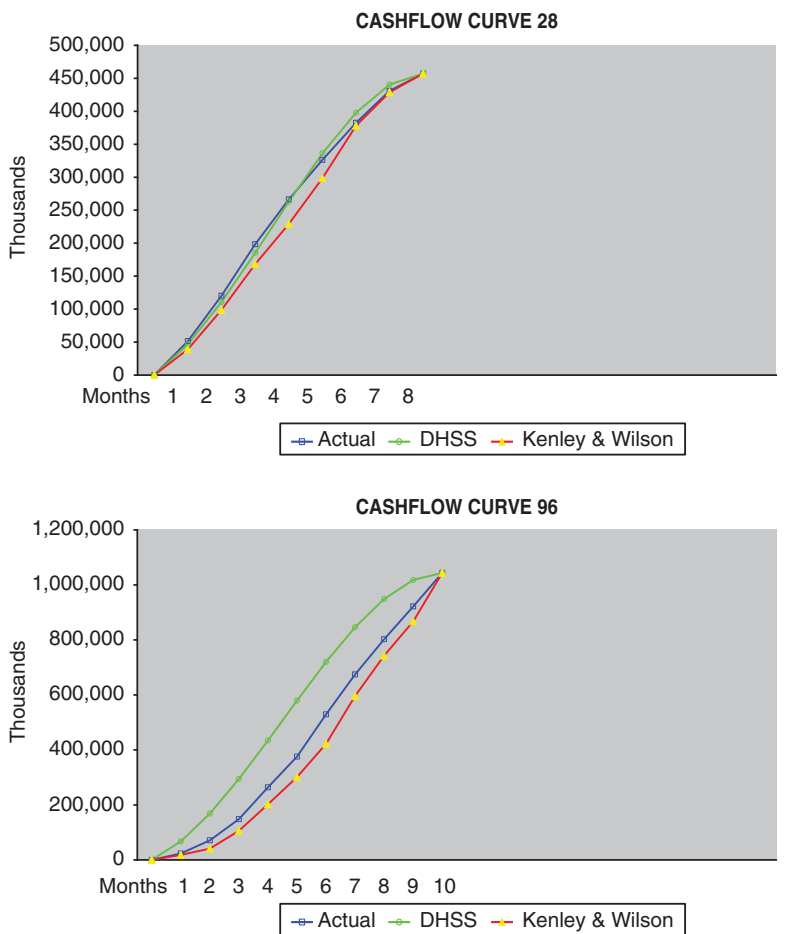

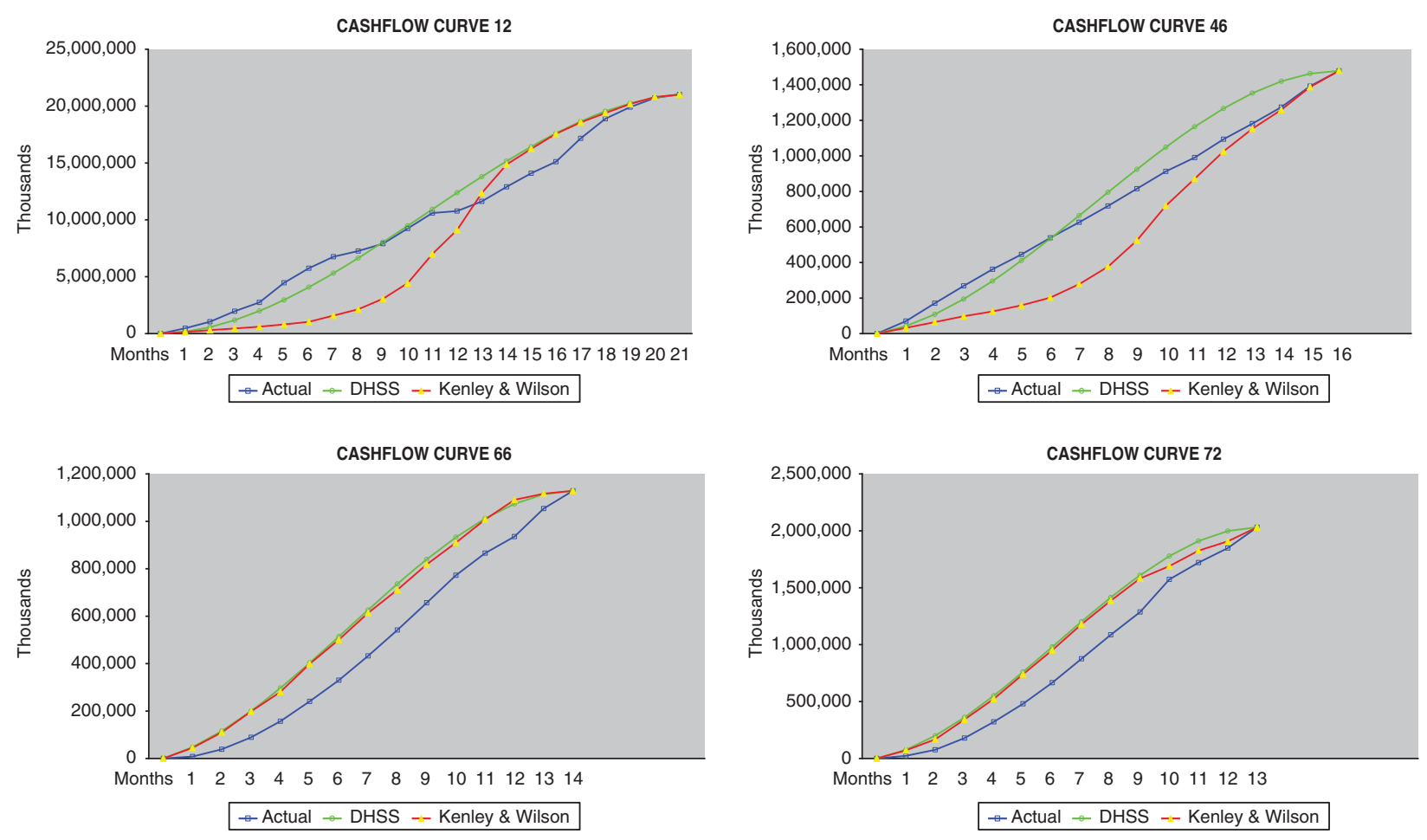

Fig. 7. Cash flow curves for projects 12, 46, 66 and 72

procurement route chosen can be expected to alter that impact on payment at the various stages of the construction process. More often than not design and build construction involves greater expense at the design stage.

As it is seen from Figures 1-7, the actual project curves produced demonstrate a wide range of profiles. The cash flow curves are commonly the ' $\mathrm{S}$ ' shape, although some can be concave or convex. The project curves differ in slope and lag, some having a prolonged start or conclusion, following on from Hudson (1978) research that recognised and advised that altering parameters $C$ and $K$ changes the build-up time and run-down period and affects the rate of expenditure over the central part of the graph, respectively. Findings for the analysed sets tend to suggest that Hudson's DHSS model is best suited to a construction project procured traditionally. This observation would support literature review, since when the Hudson model was developed in 1978, the majority of projects would have been of traditional construction method, and to a traditional contract. Therefore, within this study, it is felt that projects of this type, with these two variables, would be best suited to adopt the Hudson DHSS model as a model, using the recognised parameters $C$ and $K$, that relate to the construction project contract sum.

Having used SPSS and an immense amount of time adopting the 'trial and error' approach, it has been recognised that Hudson's DHSS model is an accurate model that could be adapted slightly, through changing the parameter values, that originally only account for contract sum, to values that take account of variables investigated in this study. The parameter values recommended for the
Table 4. The parameter values recommended for the specific variables (revised parameter values for the DHSS model to take account of variables studied in this research)

\begin{tabular}{l|c|c}
\hline \multirow{2}{*}{ Variable } & \multicolumn{2}{|c}{ Parameters } \\
\cline { 2 - 3 } & $C$ & $K$ \\
\hline Refurbishment & 0.45 & 5 \\
\hline New build & -0.2 & 3.5 \\
\hline Steel frame & 0.12 & 4 \\
\hline Design and Build & 0.12 & 4 \\
\hline
\end{tabular}

specific variables have been summarised in Table 4 . These parameter values can be applied to the DHSS model, to potentially improve the accuracy of the model for the specific variables identified. These values have been shown to improve the predictive ability of the models for the respective variables of project type, form of construction and procurement type. The parameter values no longer account for the size of the construction project itself. Researching the shape of the curves needed, it is suggested in this study that for steel frame construction and design and build, altering the $C$ parameter to change the build-up time and potentially produce a more 'front loaded' curve would be appropriate to represent both of these variables. In order to find appropriate values to acknowledge and distinguish between refurbishment and new build, many trial and error techniques have been put into practice.

To support the potential of revised parameter values, the models were run again, and it can be seen that the 

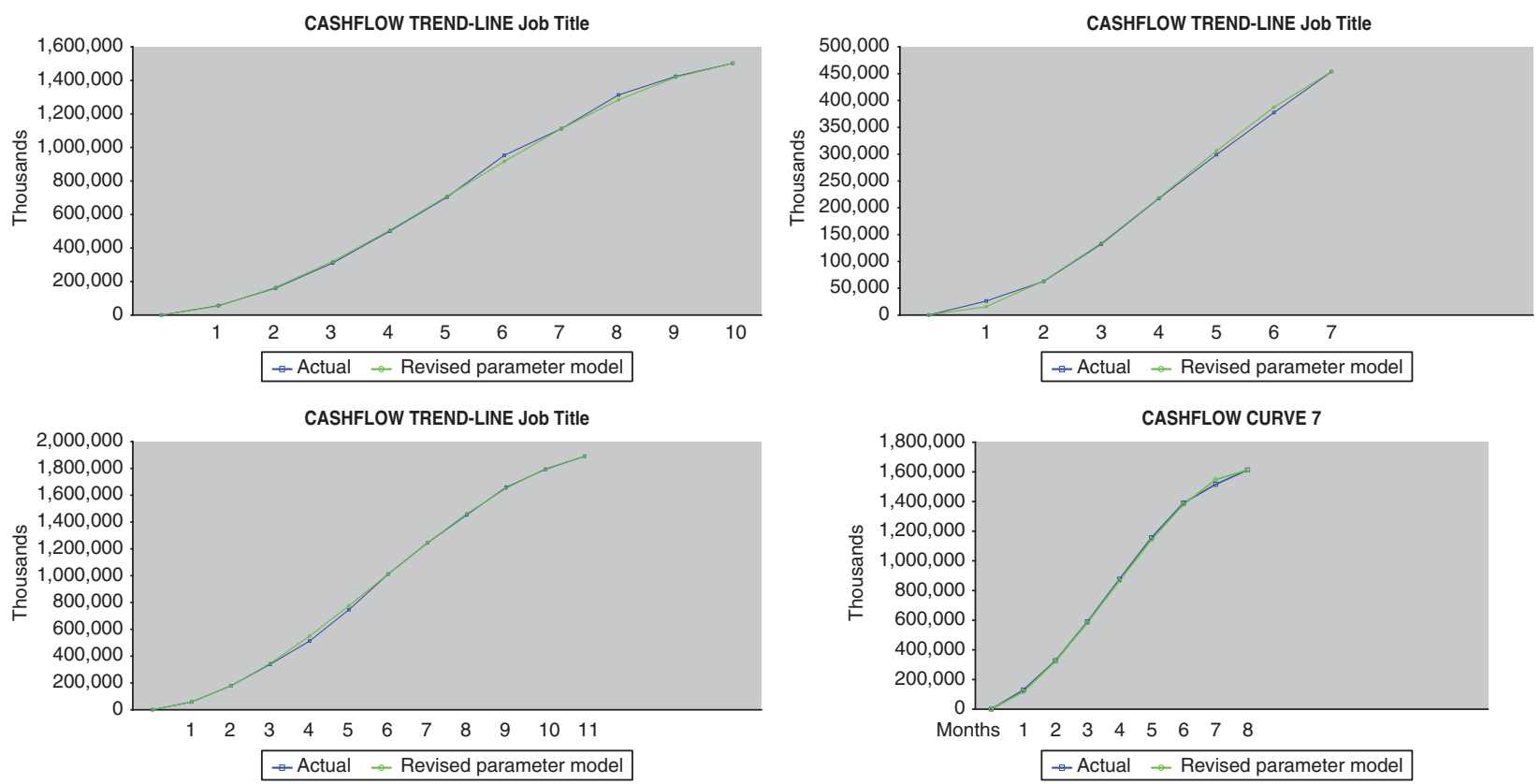

Fig. 8. Cash flow curves (for project 91, incorporating the proposed parameter values for steel frame; for project 98, incorporating the proposed parameter values for refurbishment; for project 92, incorporating the proposed parameter values for new build; for project 7 , incorporating the proposed parameter values for design and build)

suggested models matched up with the actual data closely. An example of each of these can be seen in Figure 8.

\section{Conclusions and recommendations}

In the current paper, the accuracy of cash flow models has been addressed and further investigations on these models have been carried out to determine that the models could be more accurate if they accounted for the potentially influential variables specific to individual construction projects. The main and subsidiary null hypotheses set under the 'Research Methods' heading have been proved, revealing that the independent variables (type of construction, procurement route and type of work) affect the cash flow forecast. The findings suggested that a model could be more accurate with the input of more job-specific variables.

The findings revealed that the cash flow curves are commonly the ' $\mathrm{S}$ ' shape differing in slope and lag, supporting Hudson's (1978) research. Findings revealed that Hudson's DHSS model is best suited to a construction project procured traditionally and of traditional construction. Adopting the 'trial and error' approach, it has been recognised that Hudson's DHSS model is an accurate model that could be adapted slightly, through changing the parameter values. $C$ and $K$ parameter values have been recommended for the specific variables (Table 4) to improve the accuracy of the model for the specific variables identified in this study (i.e. refurbishment, new build, steel frame and design and build). These proposed $C$ and $K$ values improved the Hudson's model as the findings matched up with the actual data closely.

This study was affected by certain limitations resulting from the collection of construction project data. As a case study approach was used, it was not possible to achieve the required number of samples with the significant number of variables to be tested to be accounted for. Another limitation of the research was that the data was collected from completed projects during the period 2002-2009. The organisation supplying the data was reluctant to release data from live projects and more recently completed projects due to the sensitivity of final account settlements. It is an acknowledged limitation of the research that the data was over a historic 7-year period; however, the method used for collection, analysis and reporting is not dependent upon the time period and consequently, the reliability of the findings is not influenced by this limitation. Furthermore, the analysis of the data from a developers perspective was not within the scope of this paper.

As it has been identified within this study, cash flow forecasting is of paramount importance to a construction project and as such, it is imperative to make use of all techniques that make this forecasting as accurate as possible. The construction industry needs to look further into how the currently used cash flow models are derived. The construction industry should look further into the factors affecting the cash flow model and put more time and funds into improving the model to its full potential. Further research should look into the effect of more variables, other than the significant three studied in this study and the researchers should analyse the data from a developers' perspective in their future researches.

\section{References}

BCIS (Building Cost Information Service of RICS). 2011. [online], [cited 8 July 2011]. Available from Internet: http://www.bcis.co.uk/site/index.aspx 
Business Dictionary. 2001. Cash flow forecast definition [online], [cited 8 December 2009]. Available from Internet: http://www.businessdictionary.com/definition/cash-flow-fo recast.html

Construction Statistics Annual Report. 2011. Office for National Statistics [online], [cited 13 November 2011]. Available from Internet:

www.ons.gov.uk/../construction/construction-statistics/... 2011.../construction-statistics-annual-report-2011.pdf

de Groot, A. 1969. Methodology: foundations of inference and research in the behavioral sciences. Belgium: Mouton \& Co. 400 p.

Hudson, K. W. 1978. D.H.S.S. expenditure forecasting method, Chartered Surveyor: Building and Quantity Surveying Quarterly 5(3): 42-45.

Investor Words. 2004. Cash flow definition [online], [cited 17 January 2010]. Available from Internet: http://www.investorwords.com/768/cash_flow.html

Jiang, A.; Malek, M.; El-Safty, A. 2011. Business strategy and capital allocation optimization model for practitioners, Journal of Management in Engineering ASCE 27(1): 58-63. http://dx.doi.org/10.1061/(ASCE)ME.1943-5479.0000033

Kaka, A. P. 1996. Towards more flexible and accurate cash flow forecasting, Construction Management and Economics 14(1): 35-44. http://dx.doi.org/10.1080/01446199600000005

Kaka, A. P.; Fortune, C. 2002. Net cash flow models: towards the black box approach, in The 18th Annual Association of Researchers in Construction Management (ARCOM) Conference, Vol. 1, 2-4 September, 2002, University of Northumbria, UK, 73-83.

Kaka, A.; Lewis, J. 2003. Development of a company-level dynamic cash flow forecasting model (DYCAFF), Construction Management and Economics 21(7): 693-705.

http://dx.doi.org/10.1080/0144619032000116561

Kaka, A. P.; Price, A. D. F. 1993. Modelling standard cost commitment curves for contractors' cash flow forecasting, Construction Management and Economics 11(4): 271283. http://dx.doi.org/10.1080/01446199300000027
Kenley, R. 2003. Financing construction: cash flows and cash farming. London: Spon Press. 273 p. http://dx.doi.org/10.4324/9780203467398

Kenley, R.; Wilson, O. D. 1986. A construction project cash flow model - an idiographic approach, Construction Management and Economics 4(3): 213-232. http://dx.doi.org/10.1080/01446198600000017

Khosrowshahi, F. 2001. Project cash flow forecasting: a mathematical approach, in The 17th Annual Association of Researchers in Construction Management (ARCOM) Conference, Vol. 1, 5-7 September, 2001, University of Salford, UK, 391-400.

Kishore, V.; Abraham, D. M.; Sinfield, J. V. 2011. Portfolio cash assessment using fuzzy systems theory, Journal of Construction Engineering and Management ASCE 137(5): 333-343. http://dx.doi.org/10.1061/(ASCE)CO.1943-7862.0000299

Liu, S.; Wang, C. 2010. Profit optimization for multiproject scheduling problems considering cash flow, Journal of Construction Engineering and Management ASCE 136(12): 1268-1278.

http://dx.doi.org/10.1061/(ASCE)CO.1943-7862.0000235

Park, H.-K. 2004. Cash flow forecasting in construction project, KSCE Journal of Civil Engineering 8(3): 265-271. http://dx.doi.org/10.1007/BF02836008

Peer, S. 1982. Application of cost-flow forecasting models, Journal of the Construction Division 108(2): 226-232.

Russell, J. 1992. Decision models for analysis and evaluation of construction contractors, Construction Management and Economics 10(3): 185-202. http://dx.doi.org/10.1080/01446199200000018

Sears, G. A. 1981. CPM/COST: an integrated approach, Journal of the Construction Division 107(2): 227-238.

Skitmore, M. 1992. Parameter prediction for cash flow forecasting models, Construction Management and Economics 10(5): 397-413.

http://dx.doi.org/10.1080/01446199200000038

Andrew ROSS. He works at the Liverpool John Moores University. He is the head of the postgraduate and collaborative programmes. His research interests include cost management, cash flows and sustainability.

Katie DALTON. She graduated from Liverpool John Moores University. Her research interests include cost management and cash flows.

Begum SERTYESILISIK. He is a visiting professor at the Liverpool John Moores University and at the Berlin Technical University and she is an assistant professor at the Yildiz Technical University. Her research interests include construction management, cost management, contract management, dispute management and sustainability. 